\title{
Midlatitude nighttime D region ionosphere variability on hourly to monthly time scales
}

\author{
Feng $\operatorname{Han}^{1}$ and Steven A. Cummer ${ }^{1}$ \\ Received 8 March 2010; revised 5 May 2010; accepted 2 June 2010; published 25 September 2010.
}

[1] Significant temporal variability of the nighttime D region is well known, but its inaccessibility means that the time scales, magnitudes, and sources for that variability are not well understood. We probed the ionospheric D region by measuring the high-power broadband very low frequency (VLF) signals launched by lightning and propagating in the Earth-ionosphere waveguide. We analyzed broadband sferic data of July and August 2005 recorded by our sensors located near Duke University by comparing measured sferic spectra to model results and extracted the height of an assumed exponential electron density profile for each measurement. The measured nighttime $\mathrm{D}$ region electron density profile heights showed large temporal variations of several kilometers on some nights and relatively stable behaviors on others. The measured hourly average heights in $260 \mathrm{~h}$ ranged between 82.0 and $87.2 \mathrm{~km}$, with a mean value of $84.9 \mathrm{~km}$ and a standard deviation of $1.1 \mathrm{~km}$. The maximum variation in the $5 \mathrm{~h}$ period was around just above $4.0 \mathrm{~km}$ and the maximum variation in the $1 \mathrm{~h}$ period was around $1.3 \mathrm{~km}$, with sharper gradients observed over shorter time periods. We also observed spatial variability as large as $2.0 \mathrm{~km}$ over $5^{\circ}$ latitudes on some nights and no spatial variability on others. On some nights, the temporal variability exhibited a close correlation with the occurrence rate of lightning discharges under the probed region. This suggests that the direct energy coupling between lightning discharges and lower ionosphere can be a significant source of the D region variability. However, on other nights, the measured height temporal variability showed weak to no correlation with local lightning, displaced lightning (as would be expected for lightning-induced electron precipitation), or geomagnetic activities. These measurements suggest that nighttime $\mathrm{D}$ region variability may be driven by many sources.

Citation: Han, F., and S. A. Cummer (2010), Midlatitude nighttime D region ionosphere variability on hourly to monthly time scales, J. Geophys. Res., 115, A09323, doi:10.1029/2010JA015437.

\section{Introduction}

[2] The ionospheric $\mathrm{D}$ region is difficult to measure because the altitudes $(\sim 75-90 \mathrm{~km})$ of this region are too high for balloons to reach but too low for satellites to take in situ measurements. Most measurements were made using rockets or ground-based techniques [Sechrist, 1974]. Rocket techniques include radio propagation between ground instruments and rocket-borne equipments which is used to derive the lower ionosphere electron density profiles along the wave propagation path [Friedrich and Torkar, 2001; Friedrich et al., 2006], and Langmuir probes which detect the electron density through measuring the electrical currents to an electrode at a fixed potential [Smith, 1969]. Although these measurements are precise, the rocket techniques are local, episodical and restricted by economical factors. The ground

\footnotetext{
${ }^{1}$ Department of Electrical and Computer Engineering, Duke University, Durham, North Carolina, USA.

Copyright 2010 by the American Geophysical Union. 0148-0227/10/2010JA015437
}

based techniques include the cross modulation [Fejer, 1970], partial reflection [Gardner and Pawsey, 1953], and incoherent scatter methods [Evans, 1969; Farley, 1970; Mathews et al., 1982; Kudeki et al., 2006]. In experiments applying these kinds of methods, electron density profiles are derived by analyzing reflected waves from ionosphere. Unfortunately, the reflected waves will become very weak when the ionosphere electron density is low, e.g., nighttime $\mathrm{D}$ region.

[3] D region electron density profiles can also be derived from the VLF electromagnetic waves $(3 \mathrm{kHz}-30 \mathrm{kHz})$ since they are almost completely reflected by the lower ionosphere, propagating in the Earth-ionosphere waveguide and containing the $\mathrm{D}$ region structure information. Thomson et al. [2007] estimated the nighttime D region electron density profile from single-frequency measurements, computed average values over long paths but no information on temporal or spatial variability. Many VLF band measurements were made for $\mathrm{D}$ region perturbations, not ambient profile changes. Bainbridge and Inan [2003] studied the direct energy coupling between lightning and lower ionosphere using single frequency VLF data recorded at Huntsville (HU), 
Alabama and Arecibo (AR), and Puerto Rico stations. Peter and Inan [2004] studied the occurrence and spatial extent of $\mathrm{D}$ region perturbations caused by LEP using VLF data generated by large man-made transmitters and recorded by the Holographic Array for Ionospheric/Lightning Research (HAIL). Cheng and Cummer [2005] measured the D region disturbances caused by a strong lightning stroke through comparing the broadband VLF spectrum from the lightning stroke that occurred just before and after the strong one.

[4] A novel method of D region VLF measurement is to use the broadband radio atmospherics (called sferics) excited by lightning discharges which radiate most of energy in VLF and ELF range (3-3000 Hz) [Cummer et al., 1998]. This technique is different from those methods we mentioned above and is capable of measuring electron density profiles in large regions and potentially all azimuthal bearings since the characteristics of observed sferics excited by lightning strokes from any directions are sensitive to the average electron density profile across the wave propagation paths. Cheng et al. [2006] measured electron density profile variations of 16 nights in 2004 by fitting the Long Wave Propagation Capability (LWPC) modeled spectra to measured sferic spectra. Jacobson et al. [2007] retrieved the D region reflection height variations in 3 years by comparing the arrival time of ground waves and ionospheric echoes. However, systematic measurements of $D$ region variations showing time and spatial scales are lacking.

[5] In this work, we used the sferics excited by 61,726 lightning strokes in July and August 2005 to almost continuously monitor the $\mathrm{D}$ region variability on 59 different nights from 00 to 05 local time (LT) by comparing measured broadband VLF spectra to a series of simulated spectra. A database was set up for simulated sferics for different D region electron density profiles, azimuth bearings, and propagating distances using a finite difference time domain (FDTD) code [Hu and Cummer, 2006]. An automatic computer fitting code was used to find the best fitted $\mathrm{D}$ region electron density profile height for each sferic. The statistical results of 260 independent hourly average measurements were calculated. The temporal variations of $\mathrm{D}$ region electron density profile heights on time scales of minutes to hours were studied, as were spatial variations. Possible mechanisms for the temporal variations were explored.

\section{Data Analysis Method}

\subsection{Description of Experimental Data}

[6] The timing (with a resolution less than one millisecond), locations (with a resolution less than $500 \mathrm{~m}$ ), and peak currents of cloud-to-ground (CG) lightning used in this work are provided by the National Lightning Detection Network (NLDN) which has more than 100 sensors across the United States continent and can detect CG flashes with the peak current larger than $5 \mathrm{kA}$, with an efficiency ranging from $80 \%$ to $90 \%$ [Cummins et al., 1998]. The lightning data is combined with sferic data to find corresponding sferic waveform for a certain CG lightning stroke.

[7] The sferic data analyzed in this paper is recorded by the broadband VLF/ELF sensors located near Duke University. The sensors which are normally oriented geomagnetic northsouth and geomagnetic east-west consist of two orthogonal loop antennas and continuously monitor subionospherically propagating VLF/ELF signals excited by lightning strokes [Cheng, 2006]. The broadband VLF signals are amplified by a preamplifier at first and then digitalized at a rate of $100 \mathrm{kHz}$ with 16 bit resolution, which is controlled by a Global Positioning System (GPS) clock. The data sampling system has two working modes: continuous mode and triggering mode. In the continuous mode, the data acquisition card samples the signals continuously and records all the sferics. In the triggering mode, the system only records the sferics whose amplitudes larger than a certain threshold so as to avoid too much data accumulation. The system records the magnetic fields in both geomagnetic north-south direction and eastwest directions. These two orthogonal components and the corresponding lightning azimuth angles are used to calculate the azimuthal $\left(B_{\phi}\right)$ and radial $\left(B_{r}\right)$ of the horizontal magnetic fields. Only $B_{\phi}$ of the measured sferic signals are used. $B_{r}$ is caused by ionosphere anisotropy and its amplitude is much smaller than that of $B_{\phi}$. Therefore, using $B_{\phi}$ can avoid low signal to noise ratio (SNR) and increase the reliability of the measured results [Cheng et al., 2006; Cummer et al., 1998].

[8] Figure 1 shows six typical measured nighttime $B_{\phi}$ spectra excited by NLDN recorded lightning strokes. The fine frequency structures between $3 \mathrm{kHz}$ and $8 \mathrm{kHz}$ are a result of Earth-ionosphere waveguide mode interference. Their sensitive dependence on the $\mathrm{D}$ region electron density profile [Cummer et al., 1998] forms the basis of this measurement technique. Three sferic spectra between 0002 LT and $0308 \mathrm{LT}$ in the left frame which were generated by lightning strokes $500 \mathrm{~km}$ from the east coast of the United States on 29 July 2005 show a $3 \mathrm{~h}$ period that exhibits significant frequency changes, and thus ionosphere variability over that time. Three sferic spectra between 0142 LT and 0306 LT in the right frame which were generated by lightning strokes round $650 \mathrm{~km}$ north of Duke station on 5 July 2005 show a $2.5 \mathrm{~h}$ period in which the ionosphere was relatively stable. Although the spectra magnitudes are different between $5.5 \mathrm{kHz}$ and $8 \mathrm{kHz}$, the fine frequency structures (those peaks and valleys) positions which are closely related to ionosphere state are almost the same.

[9] In this paper, we only analyzed the sferic data in July and August 2005 since the data acquisition system worked in continuous mode in these 2 months, which made the ionospheric $\mathrm{D}$ region monitored in almost a continuous fashion. In order to make pure nighttime $\mathrm{D}$ region measurements, we choose the sferic data at least $3 \mathrm{~h}$ after sunset, 00-05 LT, or 04-09 universal time (UT). The daytime data will be analyzed in another paper because the daytime sferic component $B_{\phi}$ shows significantly different features compared to nighttime sferics. The amplitude variations between $3 \mathrm{kHz}$ and $8 \mathrm{kHz}$ from which the $\mathrm{D}$ region electron density profile height is extracted are clear in the nighttime sferic spectrum but almost disappear in the daytime sferic spectrum. In addition, only lightning strokes that occurred between 500 and $800 \mathrm{~km}$ from the receivers are considered. These propagation distances ensure that we are measuring the ionosphere in a relatively small geographic regions to minimize the spatial averaging of any variability. On the other hand, sferics generated by lightning strokes too near the receivers have fewer mode interference features and therefore contain less ionosphere information in the spectra. A criterion of $30 \mathrm{kA}$ threshold was applied to the lightning peak current selection to ensure each sferic has a favorable SNR. 

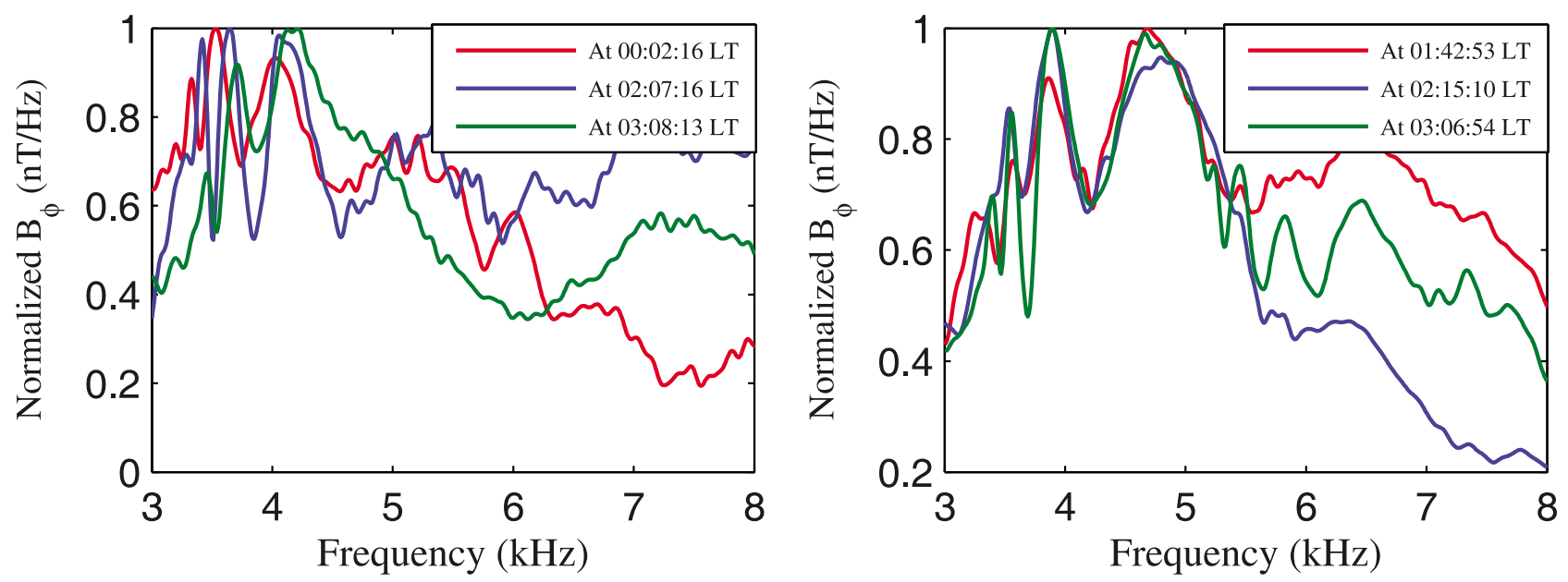

Figure 1. Three sferic spectra for lightning at different time but from almost the same location: (left) events on 29 July 2005 demonstrate strong variability of the nighttime D region, and (right) events on 5 July 2005 show little variability.

\subsection{Model Simulations of VLF Sferic Propagation}

[10] The heights of $\mathrm{D}$ region electron density profile are derived by comparing the measured sferic spectra to the FDTD simulation results. In the simulation, we use the standard D region electron density profile parameterizations of

$N_{e}(h)=1.43 \times 10^{7} \exp \left(-0.15 h^{\prime}\right) \times \exp \left[(\beta-0.15)\left(h-h^{\prime}\right)\right] \mathrm{cm}^{-3}$

with $h^{\prime}$ in $\mathrm{km}$ and $\beta$ in $\mathrm{km}^{-1}$ [Wait and Spies, 1964]. By constraining our measurements to this functional form, we can measure equivalent exponential profiles that may be different from the more complex true profiles [Goldberg et al., 1997; Smith and Klaus, 1978]. Cheng et al. [2006] showed that the sferic spectra under rocket measured electron density profiles [Mechtly and Smith, 1968; Smith and Gilchrist, 1984] and equivalent two-parameter exponential profiles are in good agreement, and also that an equivalent profile can reproduce the major propagation effects. This equivalent exponential profile has been successfully used in VLF measurements [Cummer et al., 1998; McRae and Thomson, 2000; Cheng et al., 2006; Thomson et al., 2007]. The parameter $h^{\prime}$ controls the height of the electron density profile while $\beta$ controls the sharpness of the profile. The ion density profiles are not well constrained in measurements. We performed FDTD model simulations and found that an increase of 10 times of the ion density only affects the amplitude of the spectrum but has a negligible effect on waveguide mode interference patterns from which the equivalent exponential profile height is extracted. Therefore, the classic ion density profiles [Narcisi, 1971; Cummer et al., 1998] are used in this work. There are also uncertainties in the D region collision frequency profiles [Phelps and Pack, 1959; Thrane and Piggott, 1966; Friedrich and Torkar, 1983]. We performed FDTD model simulations and found that a change from the profile adapted from Thrane and Piggott [1966] to the profile from Wait and Spies [1964], around an increase of 10 times of the density, can shift the sferic spectrum, which is equal to a shift caused by $0.2 \mathrm{~km}$ $h^{\prime}$ change. It means an error of $0.2 \mathrm{~km}$ of the measured $h^{\prime}$ is caused by an uncertain of 10 times of the collision frequency density. In this work, we use the profiles [Wait and Spies, 1964; Morfitt and Shellman, 1976; Cummer et al., 1998] which are widely used in VLF literature. The insensitivity of the waveguide mode interference pattern of a spectrum on ion densities and collision frequencies means the derived equivalent exponential profile height is precise and reliable.

[11] Earth's background magnetic field affects the radio wave significantly since the motions of charged particles in the ionosphere plasma are subject to the static field and the currents generated by those motions are coupled into the Maxwell equations and lead to a complicated process describing the wave propagation in magnetized cold plasma. The magnetic field is treated as homogenous in the whole simulation domain with magnitude $5 \times 10^{4} \mathrm{nT}$ and the dip angle $65^{\circ}$ since the simulated sferic wave propagation is in the midlatitude and the size of simulation domain is much smaller than Earth radius. And the azimuth dependence of the wave propagation is also included.

[12] The upper boundary of the simulation domain is modeled by the two-parameter electron density profile described by (1). The lower boundary, the ground, is treated as a Perfect Electrical Conductor (PEC) in previous work [Cummer, 2000; Ma et al., 1998]. Since the measurement of $\mathrm{D}$ region electron density profiles in this work mainly depends on the lower-frequency range (below $8 \mathrm{kHz}$ ), the PEC approximation will not affect the results because the true ground can be treated as a PEC for lower-frequency signals [Balanis, 1989]. FDTD simulations showed that a change from the PEC boundary to soil or water mainly affects upper VLF frequency range and the spectrum change below $8 \mathrm{kHz}$ is negligible. Perfect Matched Layers (PML) are used to absorb outward propagating sferic waves so as to avoid artificial reflections [Hu and Cummer, 2006].

[13] The details of the source lightning return stroke do not affect the sferic spectrum processing and in the FDTD simulations we use the model given by Jones [1970] and Dennis and Pierce [1967] which was also used by Cheng et al. [2006]. 

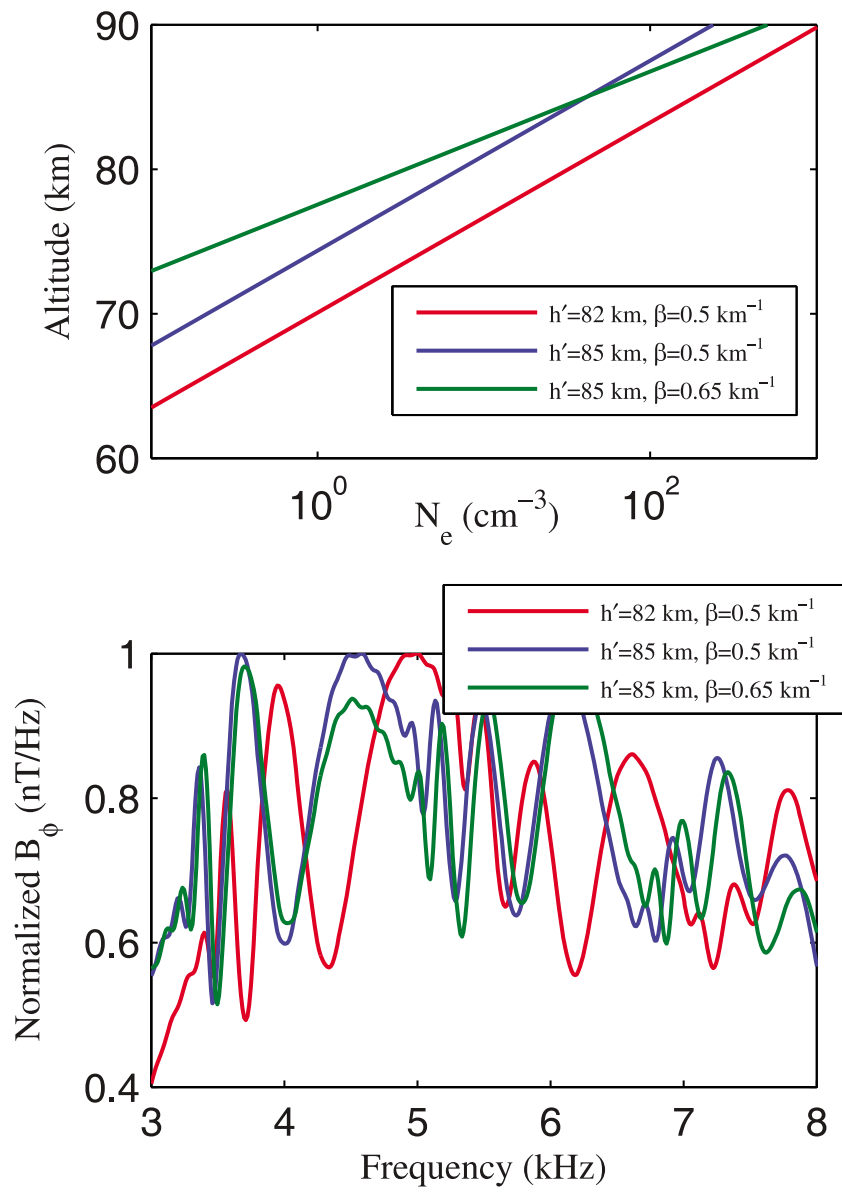

Figure 2. Three typical nighttime $\mathrm{D}$ region electron density profiles and the corresponding simulated sferic spectra under those profiles: (top) electron density profiles and (bottom) sferic spectra. The VLF spectrum in lower frequency is very sensitive to $h^{\prime}$ but much less sensitive to $\beta$.

\subsection{The Influence of D Region Parameters on VLF Spectra}

[14] The parameters $h^{\prime}$ and $\beta$ have different effects on a sferic spectrum [Cummer et al., 1998] and this is illustrated in Figure 2. The top frame shows three sample electron density profiles and the bottom frame shows the corresponding simulated sferic spectra for those profiles. A larger $h^{\prime}$ alters the positions of the waveguide mode interference fringes by lowering the cutoff frequencies of all modes in the waveguide [Cummer et al., 1998]. These fringe positions can be reliably measured even from individual sferics, enabling measurements of $h^{\prime}$.

[15] In contrast, in this lower VLF frequency range from $\sim 3$ to $8 \mathrm{kHz}$, a change in $\beta$ affects the magnitudes of those fringes but very minimally changes the positions of the fringes [Cheng et al., 2006], as shown in the bottom frame of Figure 2. This magnitude difference has been attributed to improved reflection from a sharper ionosphere, leading to lower attenuation of near-cutoff waveguide modes [Cummer et al., 1998]. We find that, in practice, it is difficult to use this amplitude change to infer $\beta$ because variations in received signals, perhaps due to small differences in lightning current waveforms and channel orientations, are too large. At present we are developing a technique for independently measuring $\beta$ from modal interference fringes at higher VLF frequencies.

[16] Consequently, in this work, we only report measurements of the variability of $h^{\prime}$, and we assume the long-term average nighttime value of $\beta=0.65 \mathrm{~km}^{-1}$ measured by Thomson et al. [2007]. Although not a complete measurement of $\mathrm{D}$ region electron density profile variability, the insensitivity of our measurement approach to $\beta$ means that our measurements of $h^{\prime}$ are reliable, and the reported temporal and spatial variations are real and quantitatively meaningful.

[17] The modal interference fringe pattern sensitively depends on propagation distance, as shown in Figure 3. For the same electron density profile, larger propagation distance causes the spectrum stretched, i.e., the fine frequency structures caused by waveguide mode interferences shift up in frequency. The effect of the propagation direction relative to the background magnetic field azimuth also influences the spectrum but less sensitively than distance, as also shown in Figure 3. For this reason our simulations require precise values of propagation distance for comparison, but less precise values of propagation azimuth.

\subsection{Profile Height Measurement}

[18] In order to extract the parameter $h^{\prime}$ from a measured sferic spectrum, we compare the measured spectrum to a series of simulated sferic spectra from the FDTD model simulations under different electron density profiles. A simulated sferic database was setup for different lightning distances, azimuth angles (bearing clockwise from north of Duke station) and D region electron density profiles. Propagation distances vary with step $20 \mathrm{~km}$; azimuth angles vary from 0 to 360 degrees with step 30 degrees; electron density profiles were modeled with $h^{\prime}$ changes from 80 to $88 \mathrm{~km}$ with step $0.2 \mathrm{~km}$, and $\beta$ is fixed to be $0.65 \mathrm{~km}^{-1}$. An automatic fitting algorithm was constructed to find the best fitted simulated sferic spectrum for each recorded sferic excited by a lightning stroke in certain azimuth and distance, i.e., to derive the electron density profile parameter $h^{\prime}$ for $\beta=0.65 \mathrm{~km}^{-1}$ across the wave propagation path.

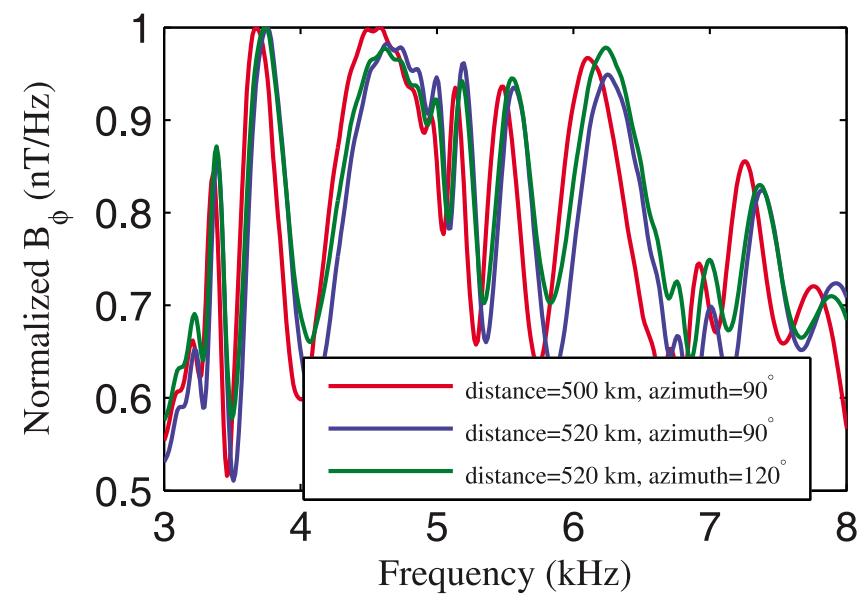

Figure 3. The comparison of simulated sferics under the same ionosphere profile but for different distances and azimuth angles. The distance increase of $20 \mathrm{~km}$ causes the sferic spectrum shifting to upper frequency, while azimuth angle change of 30 degrees causes no shift. 
[19] The $h^{\prime}$ is derived in following four steps. At first, the program code fetches from the database the simulated sferics that have the azimuth angle and two distances nearest to the azimuth angle and distance of the measured sferic. Then, it selects several simulated sferic spectra which have one peak aligned with the biggest peak of the measured sferic spectrum in frequency range 3-4 kHz. This range has the largest sferic energy distribution and thus the positions of fine frequency structures caused by waveguide mode interference are clear due to the high SNR. These selected simulated sferics are termed "first batch sferics." Usually, the best fitted sferic is one of the "first batch sferics." But many other sferics are also included in the "first batch sferics" because the $h^{\prime}$ change causes those peaks shift in 3-4 kHz frequency range and other peaks can also align with the biggest peak of the measured sferic spectrum. And the "second batch sferics" are generated by adding other sferics corresponding to $h^{\prime} 0.2 \mathrm{~km}$ smaller and $0.2 \mathrm{~km}$ larger than the $h^{\prime}$ for each of the "first batch sferics" to them. This is used to avoid the absolute dominance of the biggest peak alignment among all those peaks in 3$4 \mathrm{kHz}$ frequency range.

[20] In the second step, the fine frequency structures caused by waveguide mode interference in frequency range $3-8 \mathrm{kHz}$ are extracted from both the "second batch sferics" spectra and the measured sferic spectrum through subtracting a sferic spectrum by a smooth spectrum extracted from that using zero phase shift low pass filter and treated as the spectrum of VLF waves before propagation in the Earth-ionosphere waveguide [Cummer et al., 1998]. The frequency range is enlarged to $3-8 \mathrm{kHz}$ since most fine frequency structures caused by waveguide mode interference are contained in this range. The correlation between those fine frequency structures of the measured sferic spectrum and the "second batch sferics" spectra are calculated. Three fitted sferic spectra corresponding to three largest correlation coefficients are selected. These three selected sferics are termed "third batch sferics." We choose three not only one because the fitting having the largest correlation coefficient does not necessarily have the best fine frequency structures alignment. However, if the fine frequency structures are not well aligned, the correlation coefficients are definitely small. The correlations are performed between those fine frequency structures caused by waveguide mode interference but not the original spectra in order to avoid the effect of difference between practical lightning current spectrum and the lightning spectrum used in the simulation on the correlation coefficients comparison.

[21] Figures $4 \mathrm{a}$ and $4 \mathrm{~b}$ show this procedure. The sferic spectra fitting between measured and simulated is more obviously shown by the processed signal comparison which is actually the fine frequency structures caused by mode interference in $b$ than by original spectra in $a$. It is clear that the spectra fitting for $h^{\prime}=85.4 \mathrm{~km}$ is better than that for $h^{\prime}=$ $86.4 \mathrm{~km}$ due to the position alignments of the fine frequency structures. The magnitudes of those fine frequency structures are not important since they have no relationship with the waveguide modes. The "third batch sferics" corresponding to $h^{\prime}=85.2,85.4$ and $85.6 \mathrm{~km}$ have the largest correlation coefficients. The third step is to compare the average fine frequency structure alignment errors between the "third batch sferics" spectra and the measured sferic spectrum and the $h^{\prime}$ for the simulated spectrum that has the least mean fine frequency structure alignment error is the best fitted result. In most cases, the $h^{\prime}$ having the largest correlation coefficient also has the least mean error. And finally, linear interpolation is applied to two best fitted $h^{\prime}$ for two different distances used in simulation that are nearest to the lightning distance to calculate the final best fitted $h^{\prime}$ value according to distance differences.

[22] Figure 4c shows the typical correlation coefficients between the measured and simulated processed signals for different $h^{\prime}$ values. The $h^{\prime}=85.4 \mathrm{~km}$ simulation gives the best fit and is usually the "measured" value. The width of the correlation indicates the uncertainty in measured $h^{\prime}$ from a single sferic. In this case, the correlation coefficient drops to approximately $60 \%$ of the maximum value at $\pm 0.6 \mathrm{~km}$ from the best value. This indicates a typical uncertainty of $\pm 0.6 \mathrm{~km}$ in $h^{\prime}$ from a single sferic. This uncertainty can be improved by averaging many single sferic measurements in a narrow time window.

[23] Figure 4d shows the histogram of measured $h^{\prime}$ from 79 sferics in a $5 \mathrm{~min}$ window for lightning strokes from almost the same location on 1 July 2005 . The $\mathrm{D}$ region $h^{\prime}$ is stable during that $5 \mathrm{~min}$ and we thus expect that the distribution of individual $h^{\prime}$ measurements should be as wide as the uncertainty in a single measurement. The measured $h^{\prime}$ had a mean value of $84.4 \mathrm{~km}$ and standard deviation of $0.63 \mathrm{~km}$. This $0.6 \mathrm{~km}$ standard deviation matches the $\pm 0.6 \mathrm{~km}$ uncertainty we expect for a single measurement. Thus, by averaging many single measurements, we can significantly reduce the measurement uncertainty. We chose a 5 min window for averaging as this typically provides at least several tens of sferics, and thus the uncertainty reductions of 5 to 10 , and precision of $0.1 \mathrm{~km}$ or better.

[24] The maximum correlation coefficient acquired in the second step of the algorithm is used to judge the reliability of the measured $h^{\prime}$. Usually, the larger the correlation coefficient, the more reliable is the measured $h^{\prime}$ value because a larger correlation coefficient means better fitting between fine frequency structures of a measured spectrum and a simulated spectrum. We only keep single sferic measurement in which the maximum correlation coefficient is larger than 0.5 to ensure reliability of the single measurement in the averaging procedure.

\section{Statistical Results}

\subsection{Measured $\boldsymbol{h}^{\prime}$ Distribution in $\mathbf{2}$ Months}

[25] To give an overview of the $h^{\prime}$ variability in the 2 months of observation, we first compute hourly averages of $h^{\prime}$. Figure 5 shows this hourly $h^{\prime}$ distribution in July and August 2005 measured from 61,726 lightning strokes that occurred from $00 \mathrm{LT}$ to $05 \mathrm{LT}$ and $500-800 \mathrm{~km}$ from the Duke sensors. Since in the FDTD model the ground altitude is treated as constant for all simulations, the true $h^{\prime}$ values corresponding to the sea level were calculated by adding the average real ground altitude along the wave propagation path to the $h^{\prime}$ values derived from the spectra fittings. All the $h^{\prime}$ measurements shown in following sections are referenced to the sea level.

[26] Figure 5a shows the time variation of measurements on a single night as connected by a line. The maximum nightly $h^{\prime}$ variation is close to the maximum variation over 2 months. Some periods exhibit discernable slow variation across several nights (for examples, DOY215 to 230). This slow vari- 

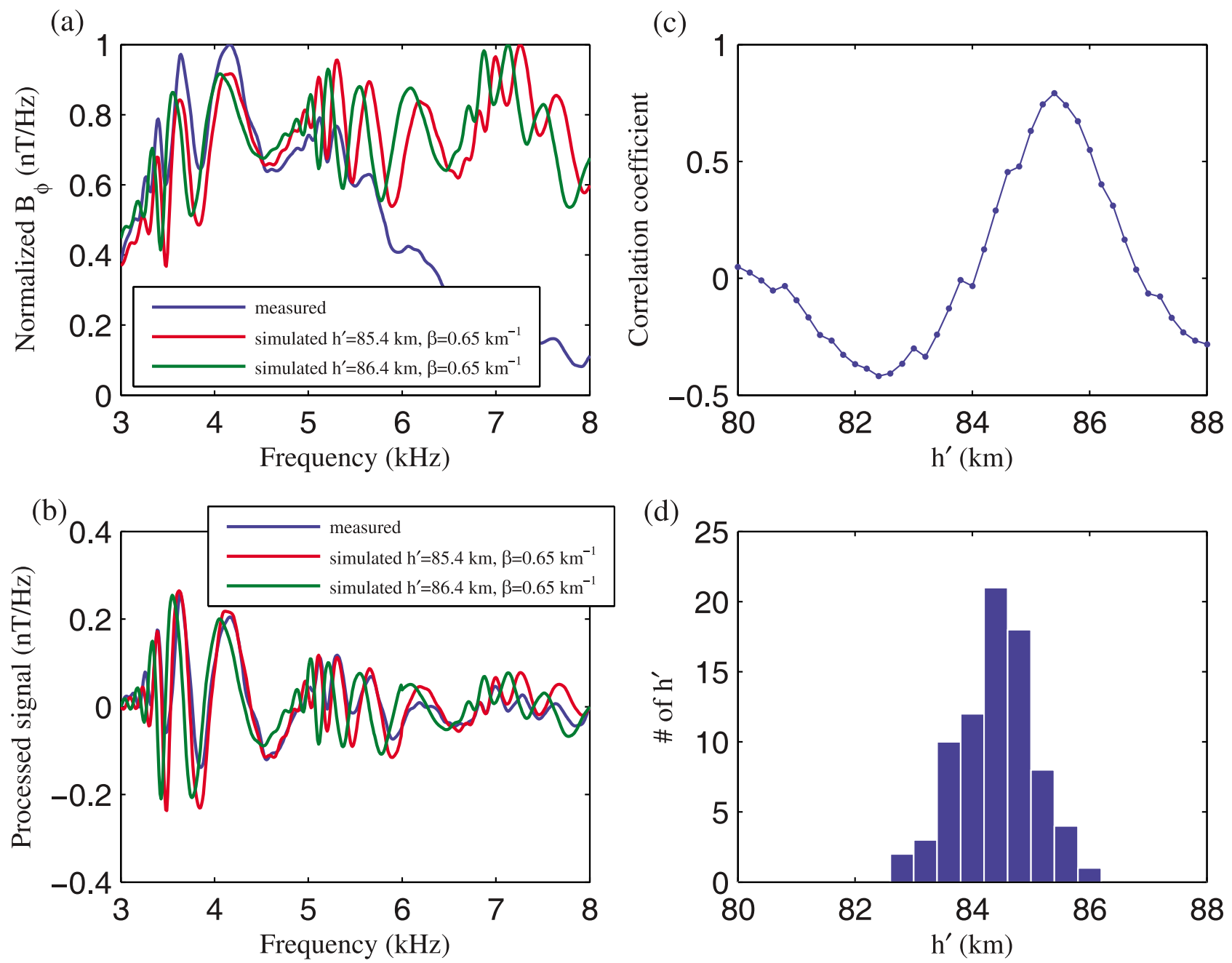

Figure 4. The sferic spectrum fitting procedure: (a) fitting for the original spectrum; (b) fitting for the peaks and valleys caused by waveguide interference; (c) correlation coefficients between the measured and simulated processed signals for different $h^{\prime}$ values; and (d) the histogram of individual $h^{\prime}$ in a 5 min window. The standard deviation is $0.63 \mathrm{~km}$.

ation may be induced by planetary waves since they were observed at periods near 16 days in stratosphere and mesosphere (20-90 km) [Forbes et al., 1995; Meyer, 1999] and can modified the electron density in lower ionosphere $(<100 \mathrm{~km})$ [Laštovička, 1994, 2001]. And sometimes, the variations are unconnected from night to night. Figure 5 b shows a close-up of a typical 5 night period. Nightly $h^{\prime}$ variations come in all forms from steady drops, to steady increases to oscillatory variations. It is notable, however, that the nights with the biggest $h^{\prime}$ changes are frequently nights with dropping $h^{\prime}$, as shown in both Figures $5 \mathrm{a}$ and $5 \mathrm{~b}$. The measured $h^{\prime}$ variations in these 5 nights indicate that the nighttime ionospheric D region is far from static and the electron density profile height variation trend can be completely different from night to night.

[27] Figure 5c is the histogram of those hourly measurements. The hourly average $h^{\prime}$ ranges from $82.0 \mathrm{~km}$ to $87.2 \mathrm{~km}$, with a mean $h^{\prime}$ of $84.9 \mathrm{~km}$ and a standard deviation of $1.1 \mathrm{~km}$. This mean value is consistent with the measurements by Thomson et al. [2007], who calculated the nighttime global average $h^{\prime}$ from single frequency VLF signals gener- ated by man-made transmitters, and found a mean value of $85.1 \pm 0.4 \mathrm{~km}$.

\subsection{Nightly Temporal Variability}

[28] Nighttime also shows variability on time scales much less than an hour. In order to illustrate the detailed measured $h^{\prime}$ variation with time, we present three examples of complete nightly $h^{\prime}$ measurements. In each case, there are several hundreds of individual measured $h^{\prime}$ from which we calculated the high-precision $5 \mathrm{~min}$ average $h^{\prime}$ values.

[29] The first example is from 29 July 2005, from 00 to $05 \mathrm{LT}$. The top frame of Figure 6 shows the $h^{\prime}$ variation extracted from 755 sferics excited by NLDN recorded lightning strokes over the ocean to the east of the sensors and at a range of $580-650 \mathrm{~km}$ from the sensors. The D region electron density profile almost maintained a constant height from $00 \mathrm{LT}$ to $01 \mathrm{LT}$, and then dropped quickly beginning at $0130 \mathrm{LT}$ from $85.8 \mathrm{~km}$ to $82.0 \mathrm{~km}$ at $0430 \mathrm{LT}$. The lack of measurements between $01 \mathrm{LT}$ and $0130 \mathrm{LT}$ as well as between $0315 \mathrm{LT}$ and $0340 \mathrm{LT}$ was due to missing data. 


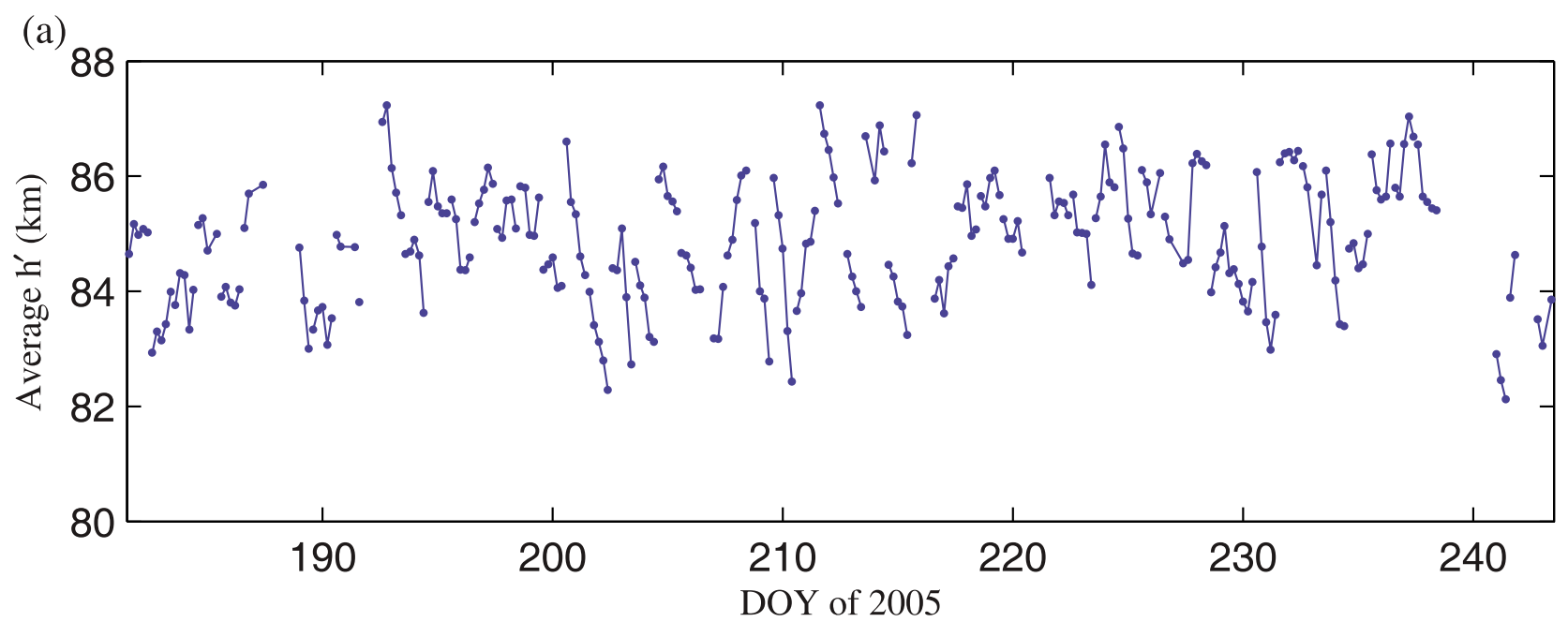

(b)

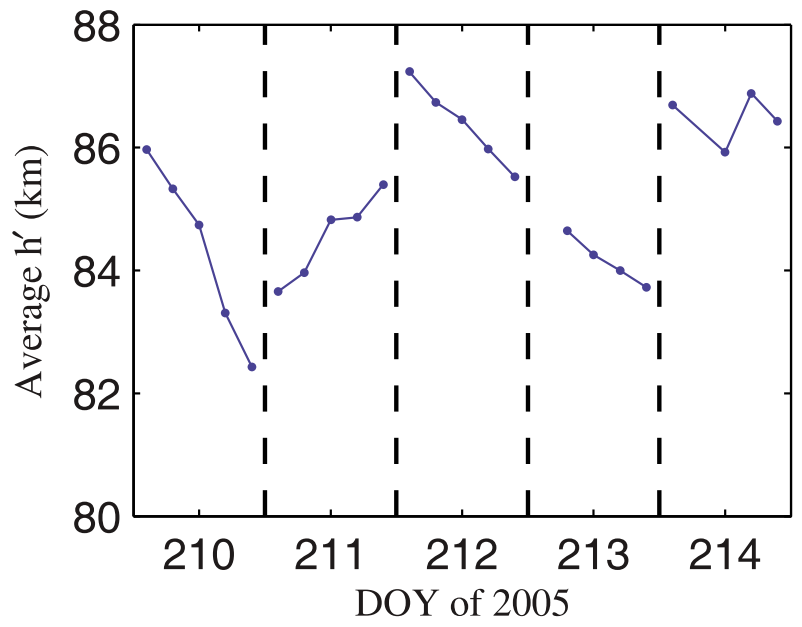

(c)

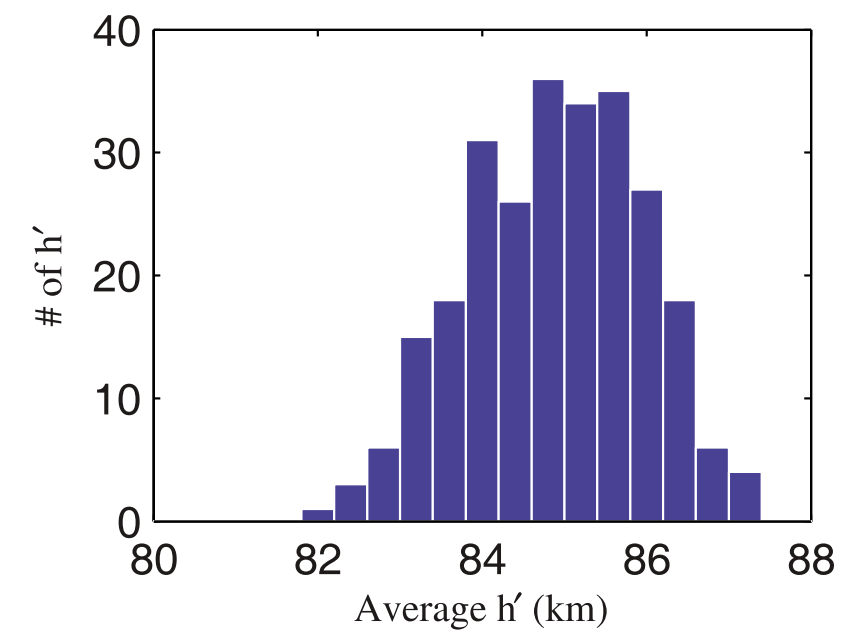

Figure 5. The hourly averaged $h^{\prime}$ distribution in 2 months: (a) hourly average $h^{\prime}$ variation in 2 months; (b) typical hourly average $h^{\prime}$ distribution in 5 nights; and (c) histogram of Figure $5 \mathrm{a}$.

[30] In contrast, the D region height varied little on 5 July 2005 , based on 524 sferics originating to the north of the sensors at a range of $550 \mathrm{~km}$. The middle frame of Figure 6 shows a nearly constant of about $84.0 \mathrm{~km}$ from $01 \mathrm{LT}$ to 05 LT. Figure 6 (bottom) shows the $h^{\prime}$ on 22 July 2005, extracted from 3137 sferics from lightning to the northwest (azimuth around 300 degrees) and 650-800 km from Duke sensors. This $h^{\prime}$ variation is complex, first dropping $1.0 \mathrm{~km}$ from $84.5 \mathrm{~km}$ to $83.5 \mathrm{~km}$ from $00 \mathrm{LT}$ to $0115 \mathrm{LT}$. Then, the $h^{\prime}$ changed sharply reaching $85.4 \mathrm{~km}$ at $0205 \mathrm{LT}$. Then, it began to drop again and finally reached $82.0 \mathrm{~km}$ at $05 \mathrm{LT}$. The lack of measurements between 0225 LT and 0250 LT was also due to missing data. This oscillation may indicate the gravity waves in the lower ionosphere which have periods of tens of minutes to several hours [Laštovička, 2001].

[31] These three examples show the wide varieties of nighttime $h^{\prime}$ variation observed. As discussed above, dropping $h^{\prime}$ dominated and was observed on 20 nights while $h^{\prime}$ on 19 nights had less than $0.5 \mathrm{~km}$ variation in $5 \mathrm{~h}$. Only 9 nights showed upward trends and 12 nights exhibited $h^{\prime}$ oscillations. The maximum observed $h^{\prime}$ variation in the $5 \mathrm{~h}$ period is a drop of just above $4.0 \mathrm{~km}$. The measured $h^{\prime}$ variation on 13 July
$2005 \mathrm{had}$ the maximum variation $1.3 \mathrm{~km}$ in $1 \mathrm{~h}$ period and sharper gradients were observed on shorter time scales.

\subsection{Nightly Spatial Variability}

[32] Unique among D region measurement techniques, this approach can be applied simultaneous in different geographic regions for an instantaneous measurement of the spatial variability of the $\mathrm{D}$ region ionosphere. Figure 7 shows two examples of simultaneous multiple $\mathrm{D}$ region measurements. Although we could measure $h^{\prime}$ using all lightning groups, for these two examples we only select lightning whose sferic waves propagate across two different regions as probing lightning in order to compare the measured $h^{\prime}$ in these regions. Two groups of lightning strokes from different directions were used to measure the $h^{\prime}$ in different regions on 5 August 2005. A total of 1176 NLDN recorded lightning strokes from the northwest of Duke sensors was used to measure the $h^{\prime}$ in region 1 and 763 strokes from the south of Duke sensors were used to measure the $h^{\prime}$ in region 2. Figure 7a shows the geographic distributions of lightning strokes during the $5 \mathrm{~h}$ nighttime period. A lightning group means there is at least one NLDN recoded lightning stroke in a $0.5^{\circ} \times 0.5^{\circ}$ geo- 

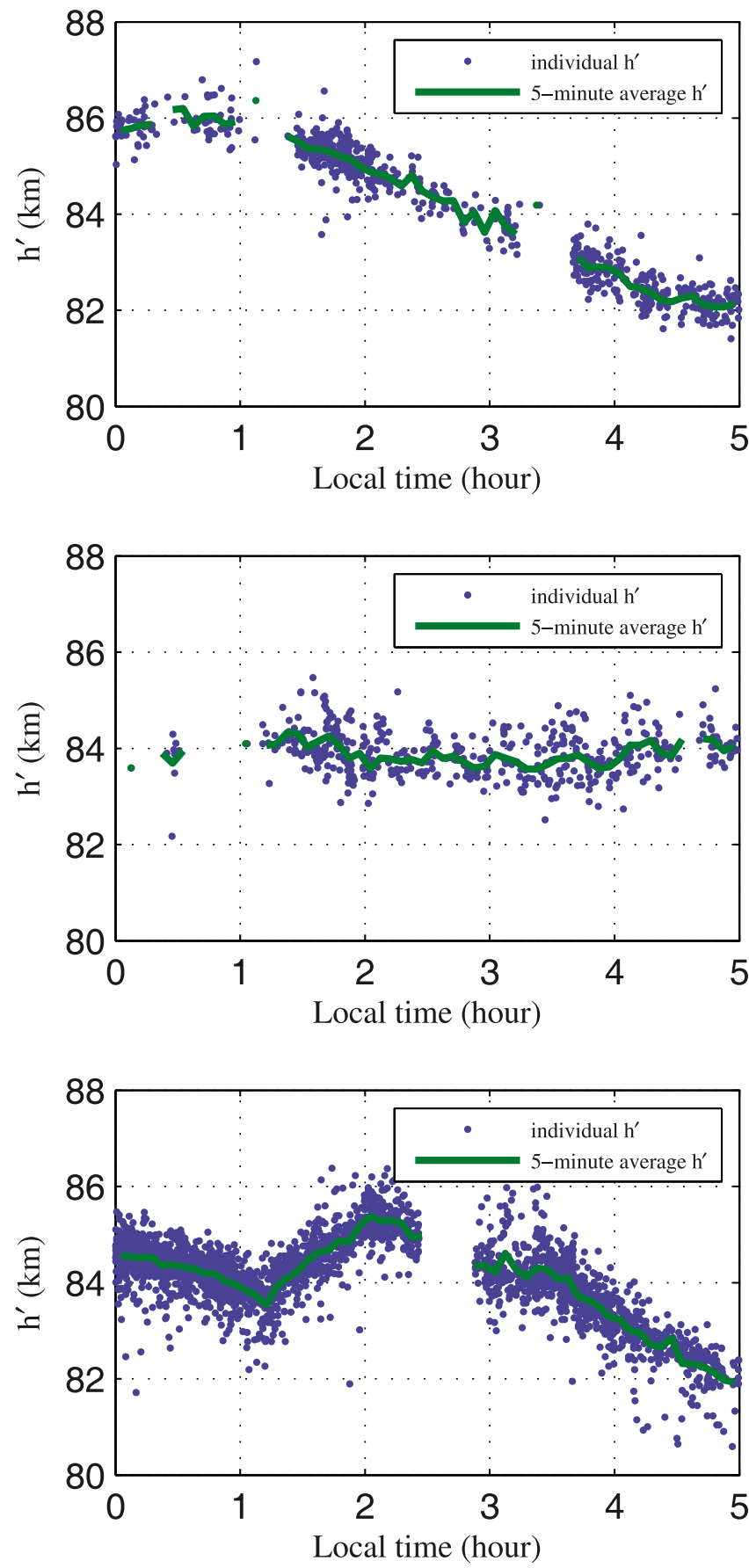

Figure 6. Typical measured $h^{\prime}$ distributions at 3 nights: (top) $h^{\prime}$ dropped quickly on 29 July 2005; (middle) $h^{\prime}$ has little variation on 5 July 2005; and (bottom) $h^{\prime}$ showed oscillations on 22 July 2005.

graphical region. Figure $7 \mathrm{~b}$ shows a significant different measured $h^{\prime}$ of $1-2 \mathrm{~km}$ in two regions. The southern region had a lower and relatively constant $h^{\prime}$, while 6 degrees latitude to the north, the $\mathrm{D}$ region was higher and descending. In contrast, there was almost no spatial variation in $h^{\prime}$ on 21 July 2005 as shown in Figures 7c and 7d. A total of 1,302 NLDN recorded lightning strokes from the northwest of Duke sensors was used to measure the $h^{\prime}$ in region 1 and 2,394 strokes from the east of Duke sensors were used to measure the $h^{\prime}$ in region 2. The measured $h^{\prime}$ in these regions $500 \mathrm{~km}$ apart descended from $84.0 \mathrm{~km}$ to $82.0 \mathrm{~km}$ during $5 \mathrm{~h}$ of nighttime with nearly identical time variations.

[33] The above examples show that the $\mathrm{D}$ region electron density profile height can but not always exhibit spatial variability. Of 59 nights in 2 months, 15 nights had useful lightning strokes in at least two different directions. Six of these showed significant spatial variability in $h^{\prime}$ while the $\mathrm{D}$ region electron density profile heights in the other nine nights showed no spatial variability over $\sim 500 \mathrm{~km}$. Nights with both lower and higher $h^{\prime}$ at higher latitudes were observed. The maximum observed $h^{\prime}$ difference across $\sim 500 \mathrm{~km}$ separation was around $2.0 \mathrm{~km}$ which appeared on 5 August 2005 and 19 August 2005. However, this $2.0 \mathrm{~km}$ difference decreased to $0.8 \mathrm{~km}$ during $1 \mathrm{~h}$ and $40 \mathrm{~min}$ period on 5 August 2005 while it maintained the same value of $2.0 \mathrm{~km}$ on 19 August 2005.

\section{Possible Mechanisms for $h^{\prime}$ Variations}

[34] The variability in the nighttime $D$ region ionosphere is driven by many processes. Scattered Lyman- $\alpha$ is a important source of nighttime middle and lower latitude D region ionization [Banks and Kockarts, 1973; Strobel et al., 1974]. High-energy ( $\geq 30 \mathrm{keV}$ ) radiation belt electron precipitation also contributes. The drivers of this precipitation can be the interaction between whistler waves and energetic particles [Jasna et al., 1992; Blake et al., 2001; Rodger et al., 2003]. However, the accuracies and availabilities of these data in certain time windows and measured regions restrict the direct quantitative comparison with our measured $h^{\prime}$ variations. Direct lightning-ionosphere coupling can also drive D and $\mathrm{E}$ region ionosphere variability. Electromagnetic pulses (EMP) radiated by lightning strokes can directly couple into the lower ionosphere, heat the electrons, change the ionization rate and perturb the VLF signal propagation [Inan et al., 1993]. Geomagnetic activity in July and August 2005 was significant with several storms and periods of $K_{p}>5$. However, we see little connection between this variability and our measured $h^{\prime}$. This is perhaps not surprising given the lower latitudes ( $\mathrm{L}=2$ to 3 ) of the probed region.

[35] Figure 8 shows a night with a remarkable correlation between $h^{\prime}$ and the rate of lightning strokes directly beneath the probed ionosphere. The top frame of Figure 8 shows lightning distribution on 21 July 2005. Although all lightning groups can be used to measure $h^{\prime}$, we only show the $h^{\prime}$ measured by lightning from the east since we are interested in $h^{\prime}$ change in region 1 . And the definition of lightning groups is explained in last section. There was no lightning to the south of the measured region, and thus nonduct LEP is not expected to produce any changes. A total of 2,394 strokes from the east of Duke sensors was used to measure the $h^{\prime}$ in region 1 and the measured results are shown in the middle frame. Distinct largely descending $h^{\prime}$ temporal variation was observed. We calculated the lightning occurrence rate per 5 min directly under the probed ionosphere in region 1 which is compared to the 5 min average $h^{\prime}$ and shown in the bottom frame of Figure 8 . The measured $h^{\prime}$ variation almost perfectly tracks the lightning occurrence variation trend. Beginning at $0030 \mathrm{LT}$, the lightning occurrence rate in region 1 increased quickly. Meanwhile, the measured $h^{\prime}$ decreased rapidly. The obvious minimum lightning occurrence rate at 0305 LT was 


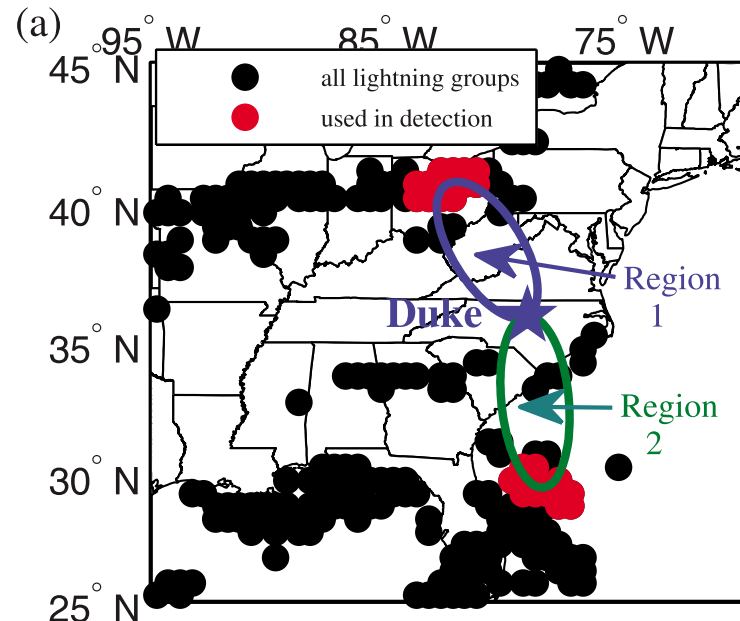

(b)

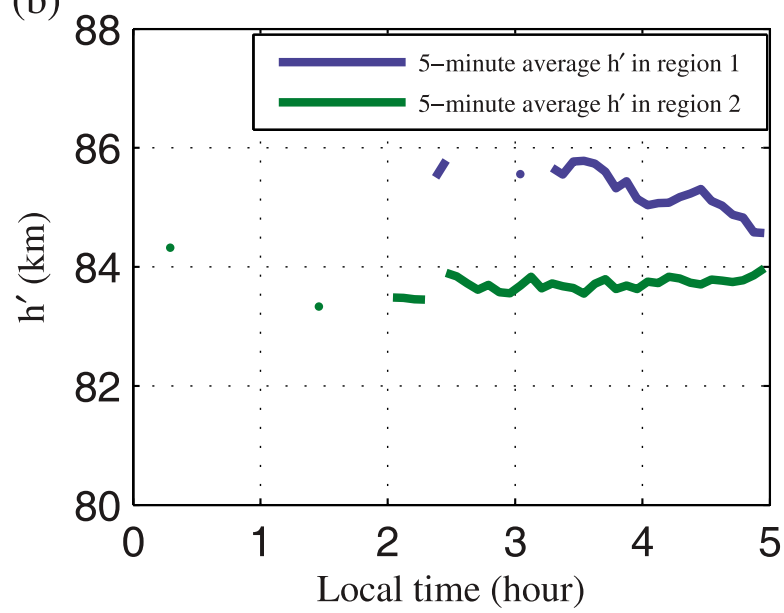

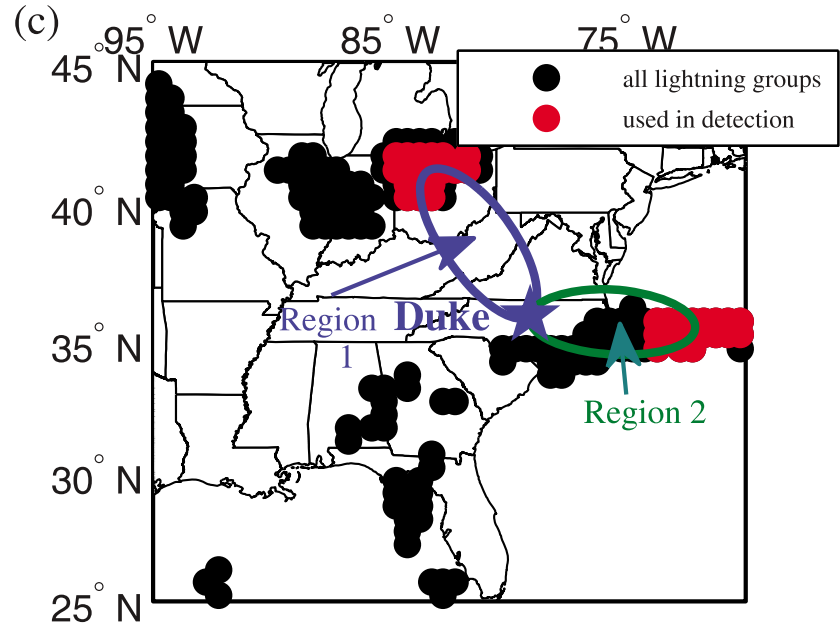

(d)

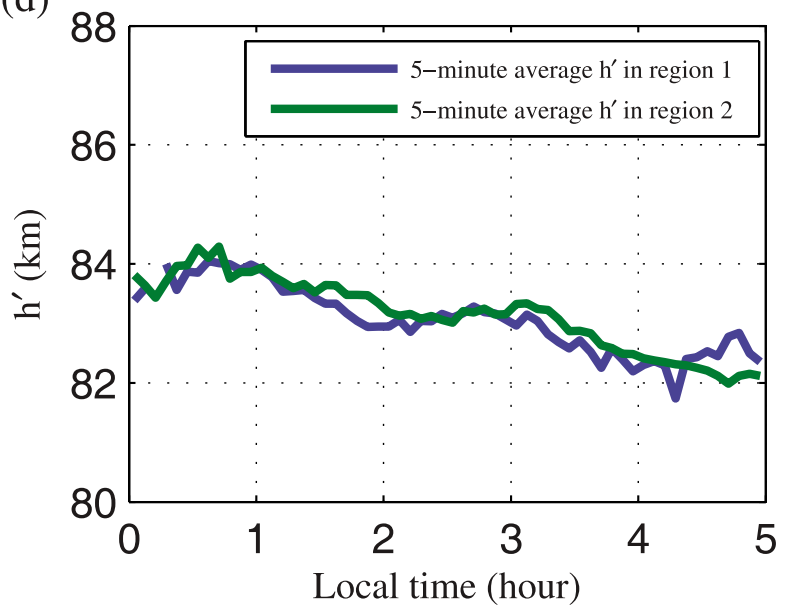

Figure 7. The $h^{\prime}$ measurements on 5 August 2005 and 21 July 2005: (a) lightning distribution on 5 August 2005; (b) 5 min average measured $h^{\prime}$ variation on 5 August 2005; (c) lightning distribution on 21 July 2005; and (d) 5 min average measured $h^{\prime}$ variation on 21 July 2005 .

corresponding to the local maximum measured $h^{\prime} 83.3 \mathrm{~km}$. The general measured $h^{\prime}$ variation trend was also consistent with the lightning occurrence rate after that time.

[36] In contrast, Figure 9 shows a night with similar large D region changes that could not be driven by local lightning strokes. The lightning distribution on 13 August 2005 is shown in the top frame of Figure 9. A total of 441 NLDN recorded lightning strokes from northwest of Duke sensors was used to measure the $h^{\prime}$ in region 1 and the results are shown in the middle frame. The measured $h^{\prime}$ using lightning in region 2 is not shown since we are not interested in the $h^{\prime}$ between those lightning strokes and the receivers. Region 1 is composed of two slightly separated regions that we lump together because the measured $h^{\prime}$ values are identical. In this case, there was almost no lightning below the probed regions, yet the $h^{\prime}$ still dropped $3.0 \mathrm{~km}$ over the night. The measured $h^{\prime}$ showed a weak correlation with the lightning rate in region 2 which is significantly south of the probed region. This could occur for nonduct LEP [Lauben et al., 2001; Peter and Inan, 2004]. The overall lightning rate, however, is much lower than in the previous case. It is very possible that the $\mathrm{D}$ region variability on this night driven by some other mechanisms.
Several mechanisms can affect the nighttime D region simultaneously and thus the measured variation can be complex. Direct energy coupling between local lightning and lower ionosphere as well as LEP are two major mechanisms that change the $\mathrm{D}$ region height.

\section{Summary and Conclusions}

[37] The broadband VLF sferics excited by lightning discharges that propagate in the Earth-ionosphere waveguide were used to measure the midlatitude nighttime $\mathrm{D}$ region electron density profile height, using an established approach based on the comparison of measured and simulated broadband VLF spectra. Measurements of 61,726 lightning strokes in July and August 2005 near Duke University provided nearly continuous measurements during $5 \mathrm{~h}$ nighttime windows over a 2 month period.

[38] Condensing these measurements to 260 independent hourly averages, the hourly $h^{\prime}$ was bounded between $82.0 \mathrm{~km}$ and $87.2 \mathrm{~km}$, with a mean value of $84.9 \mathrm{~km}$ and a standard deviation of $1.1 \mathrm{~km}$. This mean value is in close agreement with the long-term average value reported by Thomson et al. 

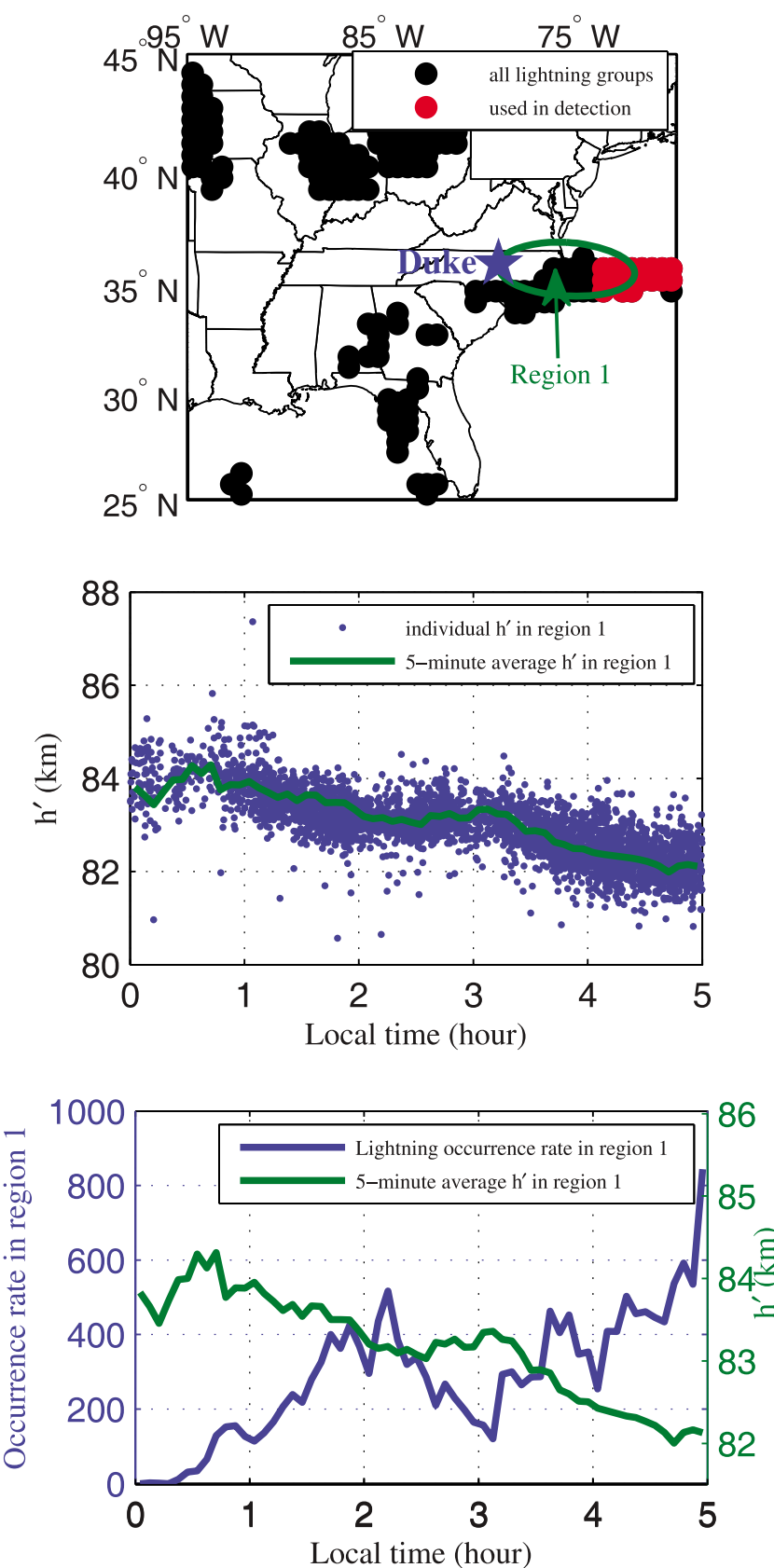

Figure 8. The derived $h^{\prime}$ distribution on 21 July 2005: (top) lightning distribution during $5 \mathrm{~h}$; (middle) derived $h^{\prime}$ variation in region 1 versus local time; and (bottom) the lightning occurrence rate compared to measured $h^{\prime}$ in 5 min window in region 1 .

[2007]. The magnitude of the hourly $h^{\prime}$ variation on a single night is almost as large as the variation observed across the entire 2 month period, indicating that much of the dynamics of the nighttime $\mathrm{D}$ region occur on time scales less than one day.

[39] Five minute average $h^{\prime}$ measurements reveal the temporal dynamics on shorter time scales. Some nights exhibit little variability while on others $h^{\prime}$ can vary by as much as $4.0 \mathrm{~km}$. The largest observed change in $1 \mathrm{~h}$ was a drop of $1.3 \mathrm{~km}$, with sharper gradients observed on even shorter time scales. Nights with steadily descending $h^{\prime}$ dominated the observations of these 2 months, although some with oscillatory variations and with ascending $h^{\prime}$ were also seen.

[40] When lightning locations are favorable, this approach also enables the measurement of simultaneous spatial gradients in $h^{\prime}$. On the nights when multipath measurements
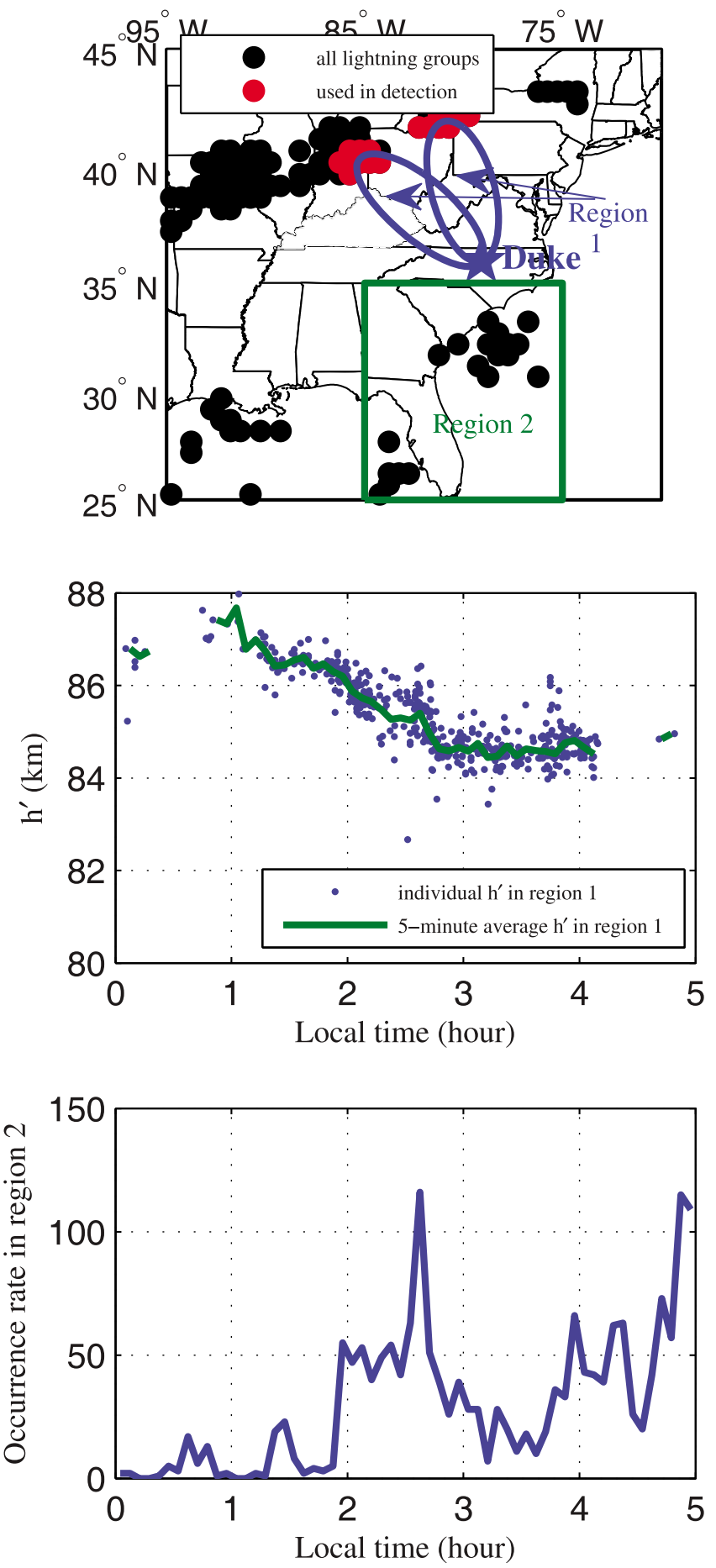

Figure 9. The derived $h^{\prime}$ distribution on 13 August 2005: (top) lightning distribution during $5 \mathrm{~h}$; (middle) derived $h^{\prime}$ variation in region 1 versus local time; and (bottom) the lightning occurrence rate in $5 \mathrm{~min}$ window in region 2 . 
could be made, significant gradients on spatial scales of approximate $500 \mathrm{~km}$ were observed about half of the time. The maximum observed $h^{\prime}$ difference for two different probed regions was $2.0 \mathrm{~km}$. Gradients in which $h^{\prime}$ increases to the north and to the south were both observed, and sometimes the temporal variation of $h^{\prime}$ in locations $500 \mathrm{~km}$ apart could be significantly different.

[41] In an effort to understand some of the possible sources driving the observed variability, we examined the observed variations in the context of local and spatial offset lightning rates. On one night, a remarkably close correlation was observed between $h^{\prime}$ and the rate of lightning strokes occurring directly under the probed ionosphere. This overall lightning rate on this night was the highest observed in the data set. This connection suggests that either direct lightning coupling to the ionosphere or ducted lightning-induced electron precipitation can drive significant $\mathrm{D}$ region variability on time scales from minutes to hours. However, many other nights with significant variability reveal no such clear correlation, which probably reflects the many possible drivers of $\mathrm{D}$ region electron density variability.

[42] Acknowledgments. This research was supported by an NSF Aeronomy Program grant. We thank Gaopeng Lu and Jingbo Li for suggestions.

[43] Philippa Browning thanks Martin Friedrich and another reviewer for their assistance in evaluating this paper.

\section{References}

Bainbridge, G., and U. S. Inan (2003), Ionospheric D region electron density profiles derived from the measured interference pattern of VLF waveguide modes, Radio Sci., 38(4), 1077, doi:10.1029/2002RS002686.

Balanis, C. A. (1989), Advanced Engineering Electromagnetics, chap. 4, p. 150 , John Wiley, New York.

Banks, P. M., and G. Kockarts (1973), Aeronomy, Academic, New York.

Blake, J. B., U. S. Inan, M. Walt, T. F. Bell, J. Bortnik, D. L. Chenette, and H. J. Christian (2001), Lightning-induced energetic electron flux enhancements in the drift loss cone, J. Geophys. Res., 106(A12), 29,733-29,744.

Cheng, Z. (2006), Broadband VLF measurement of large/small scale D region ionospheric variabilities, Ph.D. thesis, Duke Univ., Durham, N. C.

Cheng, Z., and S. A. Cummer (2005), Broadband VLF measurements of lightning-induced ionospheric perturbations, Geophys. Res. Lett., 32, L08804, doi:10.1029/2004GL022187.

Cheng, Z., S. A. Cummer, D. N. Baker, and S. G. Kanekal (2006), Nighttime $\mathrm{D}$ region electron density profiles and variabilities inferred from broadband measurements using VLF radio emissions from lightning, J. Geophys. Res., 111, A05302, doi:10.1029/2005JA011308.

Cummer, S. A. (2000), Modeling electromagnetic propagation in the Earth-ionosphere waveguide, IEEE Trans. Antennas Propag., 48(9), 1420-1429.

Cummer, S. A., U. S. Inan, and T. F. Bell (1998), Ionospheric D region remote sensing using VLF radio atmospherics, Radio Sci., 33, 1781-1792.

Cummins, K. L., E. P. Krider, and M. D. Malone (1998), The U. S. national lightning detection network and applications of cloud-to-ground lightning data by electric power utilities, IEEE Trans. Electro. Compatibility, 40(4), 465-480.

Dennis, A. S., and E. T. Pierce (1967), The return stroke of the lightning flash to earth as a source of VLF atmospherics, Radio Sci., 68D, 77.

Evans, J. V. (1969), Theory and practice of ionosphere study by Thomson scatter radar, Proc. IEEE, 57, 468-530.

Farley, D. T. (1970), Incoherent scattering at radio frequencies, J. Atmos. Terr. Phys, 32, 693-704.

Fejer, J. A. (1970), Radio wave probing of the lower ionosphere by crossmodulation techniques, J. Atmos. Terr. Phys., 32, 597-607.

Forbes, J. M., M. E. Hagan, S. Miyahara, F. Vial, A. H. Manson, C. E. Meek, and Y. Portnyagin (1995), Quasi 16 day oscillation in the mesosphere and lower thermosphere, J. Geophys. Res., 100(D5), 9149-9163, doi:10.1029/94JD02157.

Friedrich, M., and K. M. Torkar (1983), Collision frequencies in the highlatitude D region, J. Atmos. Terr. Phys., 45, 267-271.
Friedrich, M., and K. M. Torkar (2001), FIRI: A semiempirical model of the lower ionosphere, J. Geophys. Res., 106(A10), 21,409-21,418, doi:10.1029/2001JA900070.

Friedrich, M., K. M. Torkar, G. A. Lehmacher, C. L. Croskey, J. D. Mitchell, E. Kudeki, and M. Milla (2006), Rocket and incoherent scatter radar common-volume electron measurements of the equatorial lower ionosphere, Geophys. Res. Lett., 33, L08807, doi:10.1029/2005GL024622.

Gardner, F. F., and J. L. Pawsey (1953), A study of the ionospheric D region using partial reflections, J. Atmos. Terr. Phys., 3, 321-324.

Goldberg, R. A., G. A. Lehmacher, F. J. Schmidlin, D. C. Fritts, J. D. Mitchell, C. L. Croskey, M. Friedrich, and W. E. Swartz (1997), Equatorial dynamics observed by rocket, radar, and satellite during the CADRE/MALTED campaign: 1. Programmatics and small-scale fluctuations, J. Geophys. Res., 102(D22), 26,179-26,190, doi:10.1029/ 96JD03653.

Hu, W., and S. A. Cummer (2006), An FDTD model for low and high altitude lightning-generated EM fields, IEEE Trans. Antennas Propag., 54, $1513-1522$

Inan, U. S., J. V. Rodriguez, and V. P. Idone (1993), VLF signatures of lightning-induced heating and ionization of the nighttime D region, Geophys. Res. Lett., 20(21), 2355-2358.

Jacobson, A. R., R. Holzworth, E. Lay, M. Heavner, and D. A. Smith (2007), Low-frequency ionospheric sounding with narrow bipolar event lightning radio emissions: Regular variabilities and solar X-ray responses, Ann. Geophys., 25, 2175-2184.

Jasna, D., U. S. Inan, and T. F. Bell (1992), Precipitation of suprathermal (100 EV) electrons by oblique whistler waves, Geophys. Res. Lett., 19(16), 1639-1642, doi:10.1029/92GL01811.

Jones, D. L. (1970), Electromagnetic radiation from multiple return strokes of lightning, J. Atmos. Terr. Phys., 32, 1077.

Kudeki, E., M. Milla, M. Friedrich, G. Lehmacher, and D. Sponseller (2006), ALTAIR incoherent scatter observations of the equatorial daytime ionosphere, Geophys. Res. Lett., 33, L08108, doi:10.1029/ 2005GL025180

Lauben, D. S., U. S. Inan, and T. F. Bell (2001), Precipitation of radiation belt electrons induced by obliquely propagating lightning-generated whistlers, J. Geophys. Res., 106(A12), 29,745-29,770, doi:10.1029/ 1999JA000155.

Laštovička, J. (1994), On the transformation of planetary waves of tropospheric origin into waves in radio wave absorption in the lower ionosphere, Stud. Geophys. Geod., 38, 71-81.

Laštovička, J. (2001), Effects of gravity and planetary waves on the lower ionosphere as obtained from radio wave absorption measurements, Phys. Chem. Earth, Part C, 26, 381-386.

Ma, Z., C. L. Croskeyb, and L. C. Haleb (1998), The electrodynamic responses of the atmosphere and ionosphere to the lightning discharge, J. Atmos. Terr. Phys., 60, 845-861.

Mathews, J. D., J. K. Breakall, and S. Ganguly (1982), The measurements of diurnal variations of electron concentration in the $60-100 \mathrm{~km}$ ionosphere at Arecibo, J. Atmos. Sol. Terr. Phys., 44, 441-448.

McRae, W. M., and N. R. Thomson (2000), VLF phase and amplitude: Daytime ionospheric parameters, J. Atmos. Terr. Phys., 62, 609-618.

Mechtly, E. A., and L. G. Smith (1968), Growth of the D region at sunrise, J. Atmos. Terr. Phys., 30, 363-369.

Meyer, C. K. (1999), Gravity wave interactions with mesospheric planetary waves: A mechanism for penetration into the thermosphere-ionosphere system, J. Geophys. Res., 104(A12), 28,181-28,196, doi:10.1029/ 1999JA900346.

Morfitt, D. G., and C. H. Shellman (1976), MODESRCH: An improved computer program for obtaining ELF/VLF/LF mode constants in an Earth-ionosphere waveguide, Nav. Electron Lab. Cent., San Diego, Calif.

Narcisi, R. S. (1971), Composition studies of the lower ionosphere, in Physics of the Upper Atmosphere, edited by F. Verniani, pp. 21-56, Compositori, Bologna, Italy.

Peter, W. B., and U. S. Inan (2004), On the occurrence and spatial extent of electron precipitation induced by oblique nonducted whistler waves, J. Geophys. Res., 109, A12215, doi:10.1029/2004JA010412.

Phelps, A. V., and J. L. Pack (1959), Electron collision frequencies in nitrogen and in the lower ionosphere, Phy. Rev. Lett., 3, 340-342.

Rodger, C. J., M. A. Clilverd, and R. J. McCormick (2003), Significance of lightning-generated whistlers to inner radiation belt electron lifetimes, J. Geophys. Res., 108(A12), 1462, doi:10.1029/2003JA009906.

Sechrist, J. C. (1974), Comparison of techniques for measurement of D region electron densities, Radio Sci., 9(1), 137-149.

Smith, L. G. (1969), Langmuir probes in the ionosphere, in Small Rocket Techniques, chap. 1, pp. 1-15, edited by K. I. Maeda, North-Holland, Amsterdam. 
Smith, L. G., and B. E. Gilchrist (1984), Rocket observations of electron density in the nighttime E region using Faraday rotation, Radio Sci. 19(3), 913-924, doi:10.1029/RS019i003p00913.

Smith, L. G., and D. E. Klaus (1978), Rocket observations of electron density irregularities in the equatorial E region, Space Res., 18, 261-264.

Strobel, D. F., T. R. Young, R. R. Meier, T. P. Coffey, and A. W. Ali (1974), The nighttime ionosphere: E region and lower F region, J. Geophys. Res., 79(22), 3171-3178, doi:10.1029/JA079i022p03171.

Thomson, N. R., M. A. Clilverd, and W. M. McRae (2007), Nighttime ionospheric D region parameters from VLF phase and amplitude, J. Geophys. Res., 112, A07304, doi:10.1029/2007JA012271.
Thrane, E. V., and W. R. Piggott (1966), The collision frequency in the $\mathrm{E}$ and D regions of the ionosphere, J. Atmos. Terr. Phys., 28, 721-737. Wait, J. R., and K. P. Spies (1964), Characteristics of Earth-ionosphere waveguide for VLF radio waves, Nat. Bur. of Stand., Boulder, Colo.

S. A. Cummer and F. Han, Department of Electrical and Computer Engineering, Duke University, Durham, NC 27708, USA. (cummer@ee. duke.edu; feng.han@duke.edu) 